\title{
Is There Evidence of Any Safety Differences Among DPP-4 Inhibitors in the Treatment of People with Type 2 Diabetes Mellitus and Reduced GFR Due to Chronic Kidney Disease?
}

\author{
Marc Evans • Sylvie Dejager • Anja Schweizer • \\ James E. Foley \\ To view enhanced content go to www.diabetestherapy-open.com \\ Received: December 18, 2014 / Published online: March 18, 2015 \\ (c) The Author(s) 2015. This article is published with open access at Springerlink.com
}

Type 2 diabetes mellitus (T2DM) is the most common cause of chronic kidney disease (CKD) globally. Multiple risk factor management is essential in such patients to delay the disease progression [1]; however, the management of blood glucose presents a particular challenge, with limited treatment options available beyond exogenous insulin therapy [2-5]. Patients with T2DM and CKD are at particular risk of hypoglycemia and its adverse consequences. Dipeptidyl peptidase-4 (DPP-4) inhibitors provide a simple, oral, glucosesensitive treatment option that does not increase the risk of hypoglycemia and does not confound the comorbidities that afflict many of

Electronic supplementary material The online version of this article (doi:10.1007/s13300-015-0104-4) contains supplementary material, which is available to authorized users.

M. Evans $(\square)$

University Hospital Llandough, Cardiff, UK

e-mail: marcevans4@sky.com

S. Dejager

Novartis Pharma SAS, Rueil Malmaison, France

A. Schweizer

Novartis Pharma AG, Basel, Switzerland

J. E. Foley

Novartis Pharmaceuticals, East Hanover, USA the other drugs used to treat T2DM [2]. In addition, DPP-4 inhibitors have been shown to be associated with no further decline in estimated glomerular filtration rate (eGFR) when treating patients with CKD [2]. In recent years, several DPP-4 inhibitors have become available and have been extensively evaluated in patients with T2DM and varying degrees of renal impairment (RI). These studies have demonstrated good efficacy and tolerability of the DPP-4 inhibitor class in these patients, and have subsequently led to regulatory approval for the use in patients with T2DM and reduced eGFR due to CKD. Indeed, only exogenous insulin and DPP-4 inhibitors are indicated and now utilized widely across all thresholds of renal function, including end-stage renal disease (ESRD; Fig. 1) [2, 6-11].

Unlike linagliptin, with other DPP-4 inhibitors the drug exposure increases with decreasing renal function (Fig. 1). Thus, doses or dose frequencies are recommended to be reduced according to standard renal thresholds [2, 6-12]. However, changes in renal function should be seen as a continuum; the thresholds from mild to moderate RI and from moderate to severe RI (see Fig. 1 for definitions) are 


\begin{tabular}{|c|c|c|c|}
\hline & Mild RI & Moderate R & Severe RI \\
\hline $\begin{array}{l}\text { Estimated GFR }{ }^{6-10} \\
(\mathrm{~mL} / \mathrm{min})\end{array}$ & $\geq 50$ to $<80$ & $\geq 30$ to $<50$ & $<30$ \\
\hline \multicolumn{4}{|l|}{ DPP-4 inhibitors } \\
\hline Sitagliptin ${ }^{6}$ & 100 mg o.d. & 50 mg o.d. & $25 \mathrm{mg} \mathrm{o.d}$. \\
\hline Saxagliptin ${ }^{7}$ & 2.5 or 5 mg o.d. & \multicolumn{2}{|c|}{$2.5 \mathrm{mg} \mathrm{o.d}$. } \\
\hline Alogliptin 8 & $25 \mathrm{mg}$ o.d. & $12.5 \mathrm{mg} \mathrm{o.d}$. & $6.25 \mathrm{mg}$ o.d. \\
\hline Linagliptin ${ }^{9}$ & \multicolumn{3}{|c|}{5 mg o.d. } \\
\hline Vildagliptin ${ }^{10}$ & 50 mg b.i.d. & \multicolumn{2}{|c|}{50 mg o.d. } \\
\hline
\end{tabular}

Fig. 1 Renal function threshold and recommended dose of DPP-4 inhibitors in renal impairment patients. b.i.d. twice daily, DPP-4 dipeptidyl peptidase-4, GFR glomerular filtration rate, o.d. once daily, $R l$ renal impairment

convenient delineations based on definitions of renal function that are in common usage [13], rather than dictated by clear discontinuities in exposure. For instance, if a patient is seen at one visit with an eGFR of about $55 \mathrm{~mL} / \mathrm{min} / 1.73 \mathrm{~m}^{2}$ and a few months later at the next visit with an eGFR at approximately $45 \mathrm{~mL} / \mathrm{min} / 1.73 \mathrm{~m}^{2}$, the physician needs to be aware of this significant decline in renal function, but its impact on drug exposure will not be anywhere near the doubling of exposure implied by the following dosage strength or frequency recommendations. The labeling for sitagliptin, saxagliptin, and alogliptin recommends dosage strength adjustments depending on the level of renal function, with presumably no loss of efficacy [2, 6-8]. Vildagliptin $50 \mathrm{mg}$ efficacy is maintained when the frequency of dosing is reduced from twice daily in patients with normal renal function to once daily in patients with moderate or severe RI, in accordance with its label $[2,10]$. The dose adjustments thus require regular monitoring of renal function, which is also good clinical practice because in these patients it is important to closely monitor renal disease progression. Other than the specifications for modifications in dose or dose frequency, there appears to be no difference between each DPP-4 inhibitor with respect to their safety and tolerability in patients with T2DM and CKD [11].

In a recent review article on linagliptin [14], the authors state that "other widely available DPP-4 inhibitors are excreted predominantly via the kidneys and require consideration/ adjustment of dose or are not recommended in patients with moderate or severe RI or ESRD requiring dialysis". Such statements may cast doubt over the suitability of DPP-4 inhibitors other than linagliptin in treating patients with RI, implying that failure to adequately adjust the dose of these DPP-4 inhibitors may be associated with an increased risk of adverse effects and even nephrotoxicity. The safety and efficacy of the DPP-4 inhibitor calls as a whole has been well established in both patients with normal renal function as well as those with varying degrees of RI $[2,11]$. These data are derived from patients with stable renal function at baseline, the question, however, is-what happens when a patient's CKD progresses resulting in an increase in exposure to unchanged drug or its metabolites consequent 
upon the declining GFR? In routine clinical practice, the failure to adjust the dose of DPP-4 inhibitor according to drug's summary of product characteristics and eGFR level is likely a fairly frequent occurrence $[15,16]$. A key issue, therefore, is whether this failure in appropriate DPP-4 inhibitor dose adjustment in line with renal function translates into clinically meaningful consequences? Such concerns are further compounded by the fact that many other commonly prescribed drugs are associated with potential renal toxicity particularly when there is an increase in pharmacological exposure due to reduced clearance or catabolism [17]. However, there is no evidence for such a link between higher exposure and renal toxicity with respect to any of the available DPP-4 inhibitors.

Finally, with regard to the risk of hypoglycemia with DPP-4 inhibitors, if the dose is not adjusted according to the label in patients with moderate/severe RI, it should be appreciated that DPP-4 inhibitors do not enhance hypoglycemia risk per se because elevations in glucagon-like peptide- 1 and glucose insulinotropic polypeptide modulate insulin and glucagon secretion in a glucosesensitive manner [18].

Thus, recommendations to reduce the dose or dose frequency of DPP-4 inhibitors in patients with RI are not based on a risk of adverse effects or renal toxicity, but are aimed towards achieving drug exposure that yields the maximum efficacy. Of interest, in a study in which vildagliptin was dosed at either $50 \mathrm{mg}$ once or twice daily in patients with ESRD, both dosing regimens were well tolerated [19], with no clinically important differences noted between doses with respect to adverse events. Thus, any concern that accumulation of vildagliptin (or its renally excreted metabolites) results in an increase in renal or other toxicities is not supported by data. To our knowledge, this is also true for the entire DPP-4 inhibitor class.

In conclusion, DPP-4 inhibitors represent an appealing treatment option for the management of blood glucose control in people with T2DM and CKD. There is a wealth of literature, clinical experience, and regulatory review indicating that there is no evidence of any safety differences between the various individual agents within the class. It is important to remember that there is a continuum of renal function in patients with diabetes, with declining renal function associated with increasing age. As renal kidney dysfunction progresses, there is an increased risk of adverse clinical outcomes including acute kidney injury, falls, frailty, and mortality. Furthermore, in association with progressive RI, some coexisting conditions become more common and increase in severity, while the risk of adverse events associated with commonly used drugs such as metformin increases with declining renal function, in addition progression to ESRD can also occur in a small but significant group of people. The routine monitoring of renal function thus represents good clinical care of people with diabetes, beyond an appropriate dose adjustment of DPP-4 inhibitor. While there may be differences in the pharmacological profiles of the individual DPP-4 inhibitors in relation to renal function, there is no evidence that these translate into differences in terms of efficacy, safety, and nephrotoxic potential.

Current license recommendations for the marketed DPP-4 inhibitors with respect to renal function are based on extensive pharmacological and clinical trial data and represent the desire to ensure patient exposure to the minimal doses of drug required to ensure 
clinical efficacy. There is currently, however, no evidence to suggest that should an inadvertently inappropriate dosing of any DPP-4 inhibitor take place in the context of declining renal function translates into either nephrotoxicity or any increased risk of adverse events.

\section{ACKNOWLEDGMENTS}

All named authors meet the International Committee of Medical Journal Editors (ICMJE) criteria for authorship for this manuscript, take responsibility for the integrity of the work as a whole, and have given final approval for the version to be published. The authors thank Anuja Shah and Amit Garg (both Novartis Healthcare Private Limited, Hyderabad, India) for editorial support which was funded by Novartis. No further funding was received for publication of this manuscript.

Conflict of interest. ME has received speaker honoraria from Novartis, Novo Nordisk and Sanofi; research awards from Sanofi and Novo Nordisk; and is a member of the advisory panel for Novartis, Sanofi, and Novo Nordisk. SD is an employee of Novartis. AS is employed by and owns shares in Novartis. JEF is employed by and owns shares in Novartis.

Compliance with ethics guidelines. This article does not contain any new studies with human or animal subjects performed by any of the authors.

Open Access. This article is distributed under the terms of the Creative Commons Attribution Noncommercial License which permits any noncommercial use, distribution, and reproduction in any medium, provided the original author(s) and the source are credited.

\section{REFERENCES}

1. National Kidney Foundation. KDOQI Clinical Practice Guideline for Diabetes and CKD: 2012 update. Am J Kidney Dis. 2012;60:850-86.

2. Dejager S, Schweizer A. Incretin therapies in the management of patients with type 2 diabetes mellitus and renal impairment. Hosp Pract. 2012;40:7-21.

3. Abe M, Okada K, Soma M. Antidiabetic agents in patients with chronic kidney disease and end-stage renal disease on dialysis: metabolism and clinical practice. Curr Drug Metab. 2011;12:57-69.

4. Forxiga [summary of product characteristics]. EMA. AstraZeneca UK Limited. Last updated October 15, 2014 https://www.medicines.org.uk/emc/ medicine/27188. Accessed Nov 22, 2014.

5. Lalau JD, Arnouts P, Sharif A, De Broe ME. Metformin and other antidiabetic agents in renal failure patients. Kidney Int. 2014;87:308-22.

6. Sitagliptin [summary of product characteristics]. EMA. Merck Sharp \& Dohme Limited. Last updated November 6, 2014. http://www.medicines.org.uk/ emc/medicine/19609/SPC/. Accessed Nov 22, 2014.

7. Saxagliptin [summary of product characteristics]. EMA. AstraZeneca UK Limited. Last updated October 27, 2014. http://www.medicines.org.uk/ emc/medicine/22315/SPC/Onglyza $+2.5 \mathrm{mg}+\% 26$ $+5 \mathrm{mg}+$ film-coated+tablets. Accessed Nov 22, 2014.

8. Alogliptin [summary of product characteristics]. EMA. Takeda UK Limited. Last updated November 11, 2014. http://www.medicines.org.uk/emc/ medicine/28513. Accessed Nov 22, 2014.

9. Linagliptin [summary of product characteristics]. EMA. Boehringer Ingelheim Limited. Last updated October 29, 2014. https://www.medicines.org.uk/ emc/medicine/25000. Accessed Nov 22, 2014.

10. Vildagliptin [summary of product characteristics]. EMA. Novartis Pharmaceuticals UK Limited. Last updated June 26, 2014. https://www.medicines.org. uk/emc/medicine/20734. Accessed Nov 22, 2014.

11. Scheen AJ. Pharmacokinetics and clinical use of incretin-based therapies in patients with chronic kidney disease and type 2 diabetes. Clin Pharmacokinet. 2015;54:1-21.

12. McGill JB, Sloan L, Newman J, et al. Long-term efficacy and safety of linagliptin in patients with type 2 diabetes and severe renal impairment: a 
1-year, randomized, double-blind, placebocontrolled study. Diabetes Care. 2013;36:237-44.

13. Levey AS, Eckardt KU, Tsukamoto $\mathrm{Y}$, et al. Definition and classification of chronic kidney disease: a position statement from kidney disease: improving global outcomes (KDIGO). Kidney Int. 2005;67:2089-100.

14. Deeks ED. Linagliptin: a review of its use in the management of type 2 diabetes mellitus. Drugs. 2012;72:1793-824.

15. McFarland MS, Cross LB, Gross B, Gentry C, Tunney J, Patel UP. Drug use evaluation of sitagliptin dosing by pharmacist versus nonpharmacist clinicians in an internal medicine department of a private physician-owned multispecialty clinic. J Manag Care Pharm. 2009; 15:563-7.

16. Meyers JL, Candrilli SD, Kovacs B. Type 2 diabetes mellitus and renal impairment in a large outpatient electronic medical records database: rates of diagnosis and antihyperglycemic medication dose adjustment. Postgrad Med. 2011;123:133-43.

17. Hassan Y, Al-Ramahi R, Abd Aziz N, Ghazali R. Drug use and dosing in chronic kidney disease. Ann Acad Med Singapore. 2009;38:1095-103.

18. Schweizer A, Foley JE, Kothny W, Ahrén B. Clinical evidence and mechanistic basis for vildagliptin's effect in combination with insulin. Vasc Health Risk Manag. 2013;9:57-64.

19. Ito $\mathrm{M}$, Abe $\mathrm{M}$, Okada $\mathrm{K}$, et al. The dipeptidyl peptidase-4 (DPP-4) inhibitor vildagliptin improves glycemic control in type 2 diabetic patients undergoing hemodialysis. Endocr J. 2011;58:979-87. 